\title{
TCOM \\ Using humor to engage the public on climate change: the effect of exposure to one-sided vs. two-sided satire on message discounting, elaboration and counterarguing
}

\section{Amy B. Becker and Ashley A. Anderson}

Abstract

Keywords

DOI

Context
The research explores the differential impact of exposure to one-sided vs. two-sided satire about climate change on message processing. Analyzing experimental data $(N=141)$ we find that one-sided satire offered by The Onion ironically claiming that global warming is a hoax encourages viewers to engage in greater message elaboration and counterarguing. In contrast, two-sided satire offered by The Weather Channel that makes jokes about those who believe in vs. reject human involvement in climate change is quickly discounted. We conclude by discussing the strategic value of incorporating one-sided satirical humor in communication efforts focused on climate change engagement.

Environmental communication; Public engagement with science and technology; Science and media

https://doi.org/10.22323/2.18040207

Submitted: 24th April 2019

Accepted: 3rd July 2019

Published: 26th August 2019

Engaging citizens on the issue of climate change poses some unique challenges. Historically, much of the news coverage of climate change has presented a balanced approach, pitting the views of scientists who argue that climate change is heavily influenced by human activity against the more conservative political viewpoint that climate change does not exist or that it is natural rather than human activity that is responsible for significant shifts in temperature [Boykoff and Boykoff, 2004]. There is a general scientific consensus surrounding human induced climate change [NASA: Global Climate Change, 2019] and we have seen a shift toward more science-driven media coverage [Carrington, 2019], with journalists adopting a reporting approach that more accurately reflects the widespread scientific agreement on the topic [Hiles and Hinnant, 2014]. The conflict between scientists and the conservative opposition, however, still exists as a familiar narrative. In fact, science communication research has consistently showcased a highly politically polarized environment with individuals rejecting information inconsistent with their own personal beliefs about the causes and consequences of climate change 
[Hart and Nisbet, 2012]. Given the unique political environment surrounding climate change, it has been hard for science communicators, climate scientists, and others to cut through the clutter and promote tailored communication messages that encourage a more scientific view of climate change, rather than a view that is driven by social values and prior political orientations. One potential way to engage citizens in a more democratic, less divisive debate is to rely on alternative message types like satire to communicate about climate change [Nisbet and Scheufele, 2009].

Borrowing from extant work on the effects of exposure to political comedy on attitudes and behavior [for a review see Becker and Waisanen, 2013], recent research has tested the effects of exposure to humorous satirical messages on beliefs in global warming. For example, research by Brewer and McKnight [2015] and Brewer and McKnight [2017] found that viewing satirical content on the issue of climate change from sources like The Daily Show (TDS), The Colbert Report (TCR), and Last Week Tonight with John Oliver (LWT) bolsters existing views about climate change and the belief in a scientific consensus toward global warming, particularly among individuals who are less interested in the climate change issue. Recent work by Anderson and Becker [2018] similarly found that exposure to one-sided ironic humor positively influences belief certainty in and perceived risk of climate change, especially among viewers who are initially less likely to rate the climate change issue as important. In a similar vein, research by Skurka and colleagues [Skurka et al., 2018] showed that subjects who were assigned to view a satirical weather report were more likely to indicate an intention to engage in activism directly related to the issue of climate change by participating in a range of behaviors like contacting elected officials or volunteering with a climate advocacy organization. Finally, qualitative work by Bore and Reid [2014] found that viewing a satirical play about climate change promotes active and positive engagement with the issue debate, encouraging audience members to reflect upon and manage their feelings toward the conflict.

Research on the coverage of climate change on satirical programs like TDS and $T C R$ suggests that these programs tend to affirm the reality of climate change rather than present a balanced approach, frequently targeting climate skeptics as the butt of the joke [Brewer, 2013; Feldman, 2013]. Viewers of these programs tend to subsequently pay greater attention to stories about climate change and the environment in other news sources [Feldman, Leiserowitz and Maibach, 2011].

While research on the effects of exposure to satirical content about climate change ultimately suggests that these comedic messages might be a helpful tool in engendering greater awareness, activism, and a more civil public discourse [Boykoff and Osnes, 2019; Feldman, 2017], research has yet to explore how these satirical messages are processed by viewers and whether viewers engage differently with humorous content that offers a one-sided perspective on the issue of climate change (as has traditionally been privileged on TDS, TCR, and LWT) vs. a two-sided perspective, which is more similar to traditional news coverage of the climate change issue. In an effort to enhance our understanding of the net impact of comedic messages about climate change on issue engagement, the present investigation takes a step back to first consider how one-sided vs. two-sided satirical messages about climate change are processed, focusing on three related, yet distinct message processing variables including: (1) message discounting, (2) elaboration, and (3) counterarguing [Nabi, Moyer-Gusé and Byrne, 2007]. 
The cognitive processing of politically oriented comedy content
Research on cognitive engagement with political comedy tends to privilege a dual processing approach, relying on theoretical frameworks like the elaboration likelihood model (ELM) [Polk, Young and Holbert, 2009]. Collectively, this scholarship suggests that comedy is processed peripherally rather than centrally, with viewers expending most of their cognitive energy on simply getting the joke, or attempting to make sense of the incongruity that is present in the humor [Young, 2008]. More specifically, we know that viewers tend to simply discount comedic messages, classifying them as jokes that are not to be taken seriously, yet at the same time engage in more effortful, enhanced message processing [Nabi, Moyer-Gusé and Byrne, 2007]. This is particularly true if viewers like the comedic source or lack the ability or motivation to carefully inspect comedic claims [LaMarre and Walther, 2013; Nabi, Moyer-Gusé and Byrne, 2007].

At the same time, however, research has suggested that viewers do make an effort to connect humor with what they already know from other media sources or experiences, engaging in the process of message elaboration [Eveland Jr., 2005]. For example, Matthes [2013] found that viewers were more likely to engage in message elaboration when exposed to thematically related humor; this dynamic was particularly true for those who expressed a stronger need for humor (NFH). In contrast, work by Becker and Waisanen [2017] comparing the effects of exposure to humorous vs. serious presidential speech found that viewers were more likely to engage in message elaboration when viewing the State of the Union than when randomly assigned to view more humorous presentations from the White House Correspondents' Dinner. Finally, a study on the differential effects of exposure to straight news vs. satirical comedy interviews with politicians found that the likelihood of engaging in elaborative processing after viewing comedy depended on prior orientations toward comedy (e.g., perceived learning from comedy and an affinity for entertaining news) [Becker, 2018a].

In a similar vein, research has also shown that viewers are less likely to try to counterargue or disagree with a conflicting message present in politically humorous content [Polk, Young and Holbert, 2009]. This lack of counterargumentation is generally attributed to two related yet distinct dynamics. First, after working to understand the joke, viewers have less cognitive energy or ability to counterargue with the humor. Second, after enjoying and being entertained by the humor, viewers lack any subsequent motivation to pick apart any contradictory claims present in the jokes. At the same time, the type of humor may be a key determining factor as to whether viewers work to engage in more effortful message processing, including message discounting, elaboration, or counterarguing.

For example, research has shown that more complicated, ironic humor encourages viewers to engage less with the process of counterarguing. In effect, exposure to ironic humor lowers the ability to engage in argument scrutiny because it requires more cognitive resources to first understand the jokes [Polk, Young and Holbert, 2009]. Ironic humor by its nature is inherently complicated, literally presenting the opposite or inverse of its intended meaning [Young et al., 2019]. Viewers need a pre-established understanding of the topic or context to make sense of and actually get the ironic humor. 
More specifically, engagement with irony is likely conditional on the complexity of the humor; in fact, the relationship between ironic complexity and humor appreciation can be thought of as curvilinear in nature. Simpler ironic messages more naturally promote message enjoyment and mirth, while more complicated messages are increasingly difficult to appreciate and engage with [Burgers, van Mulken and Schellens, 2011]. For many, these more complicated ironic missives are taken literally at face value rather than appreciated as humorous, contradictory content [LaMarre, Landreville and Beam, 2009]. At the same time, research suggests that more complex humorous messages like those that rely on irony can motivate viewers to engage with a message more deeply, engaging in more - if not ultimately better - counterargumentation [Polk, Young and Holbert, 2009]. As Polk, Young and Holbert [2009] ultimately suggest, while complicated ironic messages reduce the ability to engage in effective counterarguing, they also encourage viewers to try and expend more effort to unpack contradictory claims.

More playful humor, often defined as horatian satire [Becker, 2012; Holbert et al., 2011], has been shown to encourage message discounting since the content is more often classified as a joke designed to make us laugh rather than content that is trying to persuade us to take a critical stance on an issue or topic. At the same time, more critical humor, or juvenalian satire, has been linked with decreased argument scrutiny in part because viewers are expending more cognitive resources to first understand and parse the more aggressive and judgmental content [LaMarre, Landreville, Young et al., 2014].

Overall, it is clear that not all humor types are processed equally. While research has explored the differential processing of irony vs. sarcasm and horatian vs. juvenalian satire [Becker, 2012; LaMarre, Landreville, Young et al., 2014; Polk, Young and Holbert, 2009], scholars have yet to consider the differential message processing that might result from exposure to one-sided vs. two-sided satire and its potential impact on engagement with climate change.

Objective: the differential effect of exposure to one-sided vs. two-sided climate change humor
As Feldman [2017] notes, the vast majority of satirical content focused on climate change presents a one-sided perspective. Shows like TDS, TCR and even LWT use humor to make fun of climate skeptics, promoting combative sketches that echo the one-sided scientific perspective that climate change is real and caused by human activity. To these comedians, anyone who holds a contrary or more politically conservative viewpoint is worthy of intense mockery. This orientation towards the climate change issue stands in direct contrast with traditional news content that has focused on a two-sided, heavily framed perspective of climate change that presents both the view that climate change is happening and human caused (the scientific consensus) and the idea that it is not happening, or is naturally caused if it is happening [Boykoff and Boykoff, 2004]. In fact, as Feldman [2017] argues, viewers have come to expect one-sided, pro-science content from cable comedy, but a more balanced or two-sided perspective from network and cable news.

Traditionally, research on message sidedness and persuasion has suggested that one-sided messages are inferior from a credibility standpoint and are quickly discounted by viewers [Allen, 1991]. Two-sided messages, on the other hand, are seen as rhetorically superior in that they reflect both sides of the story by presenting a central narrative and an opposing and carefully constructed 
counterargument or competitive frame [O'Keefe, 1999]. These two-sided messages, particularly ones that directly refute the original claim, encourage greater argument scrutiny among viewers [O'Keefe, 1999]. Non-refutational or less confrontational two-sided messages are ultimately less persuasive and impactful in part because of their more benign nature [Hale, Mongeau and Thomas, 1991].

Importantly, two-sided messages are often connected with the concept of inoculation in that messages that present contrasting points of view provide viewers with the necessary information to inoculate themselves (or prevent themselves, much like a vaccine) from being persuaded by contradictory or less than credible information [Compton, 2013; Compton and Pfau, 2005]. Viewing the second or alternate frame of the argument has a neutralizing effect, rendering the original message ineffective from a persuasion standpoint [Niederdeppe, Gollust and Barry, 2014; Pfau, 1992]. Often applied to the context of strategic political communication, two-sided messages can encourage viewers to simply discount the content being presented [Pfau and Burgoon, 1988]. This dynamic has proven true with respect to political attack ads and more recently with respect to political comedy in a case that focuses on Donald Trump's two-sided engagement with Saturday Night Live via Twitter [Becker, 2017; Pfau, Park et al., 2001]. In sum, two-sided messages present a counter narrative that ultimately distracts viewers from processing the original content, making it a less persuasive message overall [Becker, 2018b].

Without question, research suggests that message sidedness is an important element of persuasion and is certainly worthy of consideration when trying to analyze the impact of satirical humor that addresses a wide range of political issues, including climate change. As such, the present research considers the differential effect of exposure to two-sided playful satire from The Weather Channel (hereafter, $T W C$ ) vs. one-sided heavily ironic satire from The Onion on message discounting, message elaboration, and counterarguing. In examining message sidedness, we are also simultaneously examining the differences in complexity (highly ironic content from The Onion vs. more sarcastic content from TWC) and tone (e.g., more critical satire from The Onion vs. more playful humor from TWC) of the humor.

Given our understanding of the present state of satire focusing on climate change [Feldman, 2013], we anticipate that viewers will expect a one-sided satirical presentation, making connections between the ironic comedy content from The Onion and what they already know or have seen through other media sources. Their familiarity with this presentation will allow them to quickly counterargue the humorous content, as they try to find flaws in the speaker's argument. This process allows them to understand whether they agree with the messages being presented. In contrast, viewers should quickly discount any two-sided messaging in part because it deviates from the normal satirical discourse surrounding climate change, but mostly because it is playful and non-confrontational in orientation - it's simply funny.

Moreover, we expect that the tone of the humor will play an important role in message processing, with viewers attempting to engage more with the highly ironic, one-sided humor of The Onion even if they lack the motivation or ability to fully break down and process the message's content. In contrast, we expect the more playful, non-refutational two-sided humor presented by TWC to be quickly 
discounted by viewers as humor, who will then subsequently be less likely to engage in message elaboration or counterarguing in response to this type of two-sided, playful content. Put more formally:

H1: Viewers will be more likely to discount the two-sided humor of TWC as opposed to the one-sided satire from The Onion.

H2: Viewers will be more likely to engage in message elaboration when exposed to the one-sided satire of The Onion as opposed to two-sided content from TWC.

H3: Viewers will be more likely to counterargue the one-sided satire of The Onion rather than the two-sided satire of TWC.

Issue importance and climate change: a question of moderation?
Before proceeding with the analysis, it is important to note the potential moderating role of interest in and perceived importance of the climate change issue on message processing. As previous research on message-sidedness has shown, audience favorability toward the topic is an important moderator of a message's effectiveness [O'Keefe, 1999]. The more interested a viewer is in the issue being discussed, the more likely they are to pay attention to humorous media content, particularly if that content aligns with their prior disposition or viewpoint toward the issue [Becker, 2014; Boukes et al., 2015].

Research on political comedy effects has highlighted the potential for comedy to engage viewers across a range of complicated political issues including net neutrality and climate change [Becker and Bode, 2018; Bode and Becker, 2018; Brewer and McKnight, 2015; Brewer and McKnight, 2017]. While this research generally suggests that comedy is more impactful in engaging less politically interested individuals via the gateway effect [Feldman, 2017], we know less about the potential moderating role of issue importance on comedic message processing. While recent work has suggested that exposure to satire reinforces global warming belief certainty and risk perceptions among those who view the climate change issue as less important [Anderson and Becker, 2018], more work is still needed to tease out the differential effect of issue importance on message processing. More specifically, for the purposes of this study, it is important to consider whether there is any potential interaction between issue importance and differential exposure to one-sided vs. two-sided satirical messages on message processing. We therefore pose a research question to consider this potentially important moderating relationship:

RQ1: Does perceived importance of the climate change issue moderate the effect of exposure to humor on message processing?

Methods

A three-group experiment was created using Qualtrics. Undergraduates $(N=141)$ were recruited from a large public university in the U.S. West and a private college 
in the East. ${ }^{1}$ Students completed the online study between October 23-November 9, 2017 in exchange for extra credit.

After a pretest questionnaire measuring political interest and issue importance, subjects were randomly assigned to watch one of two experimental video clips or a control.

Subjects in the first experimental condition $(n=47)$ watched an April 2017 two-minute video entitled, "WARNING: We're saving small talk," produced by TWC about rising temperatures and the impact of climate change on casual small talk about the weather. The playful short clip was two-sided in orientation in that it showcased satirical behavior and conversation among everyday individuals who were both happy and uncomfortable with unseasonably warm temperatures and potential connections with climate change. At one point, the female reporter notes, "But today, confusion about changing climate has made weather too hot to talk about." The clip then cuts to an altercation between two surfers - one is complaining about the cold weather while the other gets in his face about "melting all the glaciers." The video then shifts to a stand-up comedian who is heckled by the crowd for making jokes about the weather "being nuts." A respected source of weather news and information in the United States, TWC is generally perceived as a straightforward media source, yet has worked as an outlet to diversify their media content to include other material including satirical humor.

Subjects in the second experimental condition $(n=48)$ watched a September 2017 two-minute video produced by The Onion entitled, "Climate Change Researcher Describes Challenge of Pulling Off Worldwide Global Warming Conspiracy." In the video, a fake climate scientist presents a one-sided, highly critical satirical argument about a conspiracy among scientists, politicians, and celebrities to persuade the public that global warming is a hoax. He begins by ironically stating, "People don't realize how much work goes into convincing the public that climate change is real. Studies, conferences, documentaries, it's all a tireless effort by the global scientific community to pull the wool over the eyes of the general public. Getting every single scientist in the entire world to propagate the lie that human activity causes global warming is a colossal undertaking." The video continues to ironically claim that the public and the media have accepted the conspiracy that climate change is manufactured. Well-known for its satirical take on news, sports, politics, science, and more, The Onion has been a familiar source for comedy in the United States for more than three decades.

Subjects in the control $(n=47)$ viewed a September 2017 two-minute video news report from Good Morning America about a worker falling from a broken Ferris wheel in North Carolina as he tries to help two boys.

All of the videos were captured via YouTube and edited to remove comments, ads, or related video suggestions. A validation mechanism was set so that subjects had to remain on the video screen for at least two minutes and could not scroll forward through sections of the video clip before advancing to the survey. A series of manipulation checks followed to confirm that subjects rated the videos correctly across a series of attributes (e.g., whether the video was entertaining, funny,

\footnotetext{
${ }^{1} \mathrm{~A}$ review of the data confirmed that there were no significant differences in the dependent variables of interest between college campuses.
} 
negative, amusing, humorous, serious, or sarcastic; 1 = "not at all entertaining," to 7 $=$ "extremely entertaining"). ${ }^{2}$ A posttest questionnaire then measured key concepts like message processing, message elaboration, counterarguing, and demographics.

Measures used in the analyses are outlined below.

\section{Dependent variables}

Message discounting $(M=2.88, S D=0.76)$ was based on agreement $(1=$ "strongly disagree," to $5=$ "strongly agree") with four related statements (Cronbach's $\alpha=$ .76) adapted from prior research [Nabi, Moyer-Gusé and Byrne, 2007] including: (1) "The speaker in the video was just joking," (2) "The video was intended more to entertain than persuade," (3) "The speaker was serious about advancing his views in the video," (reverse coded), and (4) "It would be easy to dismiss this video as simply a joke."

Message elaboration $(M=2.98, S D=.92)$ was based on agreement $(1=$ "strongly disagree," to $5=$ "strongly agree") with four related statements (Cronbach's $\alpha=$ .86) featured in previous research [Matthes, 2013] including: (1) "During the video, I intensively thought about what the speaker said," (2) "I concentrated on the arguments of the speaker," (3) "During the video, I critically reflected on what the speaker said," and (4) "I didn't really think about the message of the speech," (reverse coded).

Counterarguing $(M=2.60, S D=0.89)$ was based on agreement $(1=$ "strongly disagree," to $5=$ "strongly agree") with four related statements (Cronbach's $\alpha=$ .76) adapted from prior research [Nabi, Moyer-Gusé and Byrne, 2007] including: (1) "I found myself actively agreeing with the speaker's points," (reverse coded), (2) "I found myself actively disagreeing with the speaker," (3) "I was looking for flaws in the speaker's arguments," and (4) "It was easy to agree with the arguments made in the message," (reverse coded).

\section{Independent variables}

Experimental Condition. Random assignment to viewing either the one-sided satire of The Onion $(n=48)$, the two-sided satire from TWC $(n=48)$, or the control $(n=47)$ was included in the analysis.

Demographics. Controls for gender [the sample was $61.3 \%$ female (coded as 1)], age $(M=19.51, S D=2.15)$, identifying as a Democrat or Independent [(each variable independently dummy coded as 1); $41.5 \%$ of the sample were Democrats; $26.1 \%$ Independent/something else; $23.2 \%$ Republican]; and conservative political ideology $(M=3.54, S D=1.57 ; 1=$ "very liberal," to 7 = "very conservative") were included in the analysis.

\footnotetext{
${ }^{2}$ The manipulation checks confirmed that subjects found both satire clips comparably entertaining, funny, amusing, humorous, sarcastic, and not serious; there were no significant differences between The Onion and TWC on these evaluation items. As expected, subjects found the one-sided satire of The Onion $(M=4.31, S D=1.45)$ to be significantly more negative than the two-sided playful satire presented by $\operatorname{TWC}(M=3.04, S D=1.29) ; t(93)=4.52, p<.001$.
} 
Predispositions. A measure of political interest $(M=3.55, S D=1.07)$ was based on a response to the question: "Some people follow what's going on in government and public affairs most of the time, even when there's not an election. Others aren't that interested. Would you say that you follow what's going on in politics and government ... ( 1 = "never," 2 = "hardly at all," 3 = "only now and then," $4=$ some of the time," and $5=$ "most of the time"). Participants were also asked to indicate how important a series of issues, including climate change, were to them personally $(M=7.59, S D=2.17 ; 1=$ "not at all important," to $10=$ "very important" $)$.

Media Evaluations. Participants were asked to evaluate the media organization sponsoring the video across four attributes $(1=$ "untrustworthy," to $7=$ "trustworthy," 1 = "unreliable," to $7=$ "reliable," $1=$ "dishonest," to $7=$ "honest," and $1=$ "not credible," to $7=$ "credible"). A media evaluation index $(M=4.66, S D=$ 1.54; overall Cronbach's $\alpha=.96$ ) was based on the combined mean score for these four attributes per organization. The mean scores for The Onion $(M=4.23$; $S D=$ 1.67) and TWC $(M=4.12 ; S D=1.46)$ were comparable and there were no significant differences between the media organizations across individual attributes. ${ }^{3}$

\section{Analytical Plan}

One-way analysis of variance (ANOVA) was employed initially to assess whether there was significant variation in the dependent variables of interest across conditions. A set of independent samples t-tests followed, evaluating whether there were significant mean differences in message discounting, elaboration, and counterarguing for those assigned to view the one-sided ironic, highly critical satire presented by The Onion vs. the two-sided playfully sarcastic satire from TWC. Finally, hierarchical ordinary least squares regression (OLS) was used to more fully explore significant predictors of variation in the key dependent variables of interest and whether perceived importance of the climate change issue moderated the differential impact of exposure to one-sided vs. two-sided humor on message processing.

\section{Results}

We turn first to the ANOVA analyses which confirm that there was significant variation across conditions for the three dependent variables of interest: message discounting $F(2,132)=22.53, p<.001, \eta^{2}=.25$; message elaboration $F(2,132)=8.15$, $p<.001, \eta^{2}=.11$; and counterarguing $F(2,132)=9.40, p<.001, \eta^{2}=.13$.

Next, we review the results of the independent samples t-tests comparing mean differences in message processing variables for those assigned to view the one-sided, ironic satire put forth by The Onion vs. those assigned to view the playfully sarcastic two-sided satire put forth by TWC. As the results show, subjects who were exposed to TWC were somewhat more likely to engage in message discounting, $t(87)=1.82, p=0.073 ; M=3.38$ for TWC vs. $M=3.04$ for The Onion. Since the results of this first t-test approach but do not achieve significance, $H 1$ is not fully supported by the research. The independent samples t-tests were

\footnotetext{
${ }^{3}$ While there were slight differences in the attribute ratings for the two media organizations, none of these differences were significant. Subjects rated each organization similarly for the attributes of: trustworthy (Onion $M=4.23, S D=1.66$; $T W C M=3.89, S D=1.64$ ); reliable (Onion $M=4.12, S D=1.67$; TWC $M=3.98, S D=1.61$ ); honest (Onion $M=4.40, S D=1.71 ; T W C M=4.54, S D=1.44$ ); and credible (Onion $M=4.19, S D=1.89 ;$ TWC $M=4.07, S D=1.71$ ).
} 
significant for both message elaboration and counterarguing. Specifically, subjects assigned to view The Onion were significantly more likely to engage in message elaboration, $t(87)=3.54, p<0.001 ; M=3.42$ for The Onion vs. $M=2.75$ for TWC, and counterarguing $t(87)=2.17, p<0.05 ; M=3.01$ for The Onion vs. $M=2.60$ for TWC. $H 2$ and $H 3$ were supported. ${ }^{4}$

Next, hierarchical regression was used to further tease out any significant factors that might help to better explain variation in message discounting, elaboration, or counterarguing, and consider the potential moderating role of perceived importance of the climate change issue. Only the analysis of message elaboration is reported here, as the models for discounting and counterarguing failed to yield significant predictors beyond random assignment to the experimental conditions.

Table 1 displays the results of the hierarchical linear regression model explaining variation in message elaboration. As Table 1 shows, demographic variables were entered as block 1 , followed by predispositions in block 2 , and evaluation of the media outlets in block 3 . Block 4 features dummy variables for viewing The Onion or TWC, while block 5 includes a set of interaction terms combining importance of the climate change issue with assignment to the humorous conditions.

As the data in Table 1 show, females $(\beta=.18, p<.05)$ and Democrats $(\beta=.34, p<$ .05 ) were significantly more likely to engage in message elaboration (block 1 incremental $R^{2}=9.8 \%$ ). While not significant initially, evaluation of the media sources was significant in the final model $\left(\beta=.23, p<.10\right.$; block 3 incremental $R^{2}=$ $1.3 \%)$. Onion viewers were significantly more likely to engage in message elaboration $\left(\beta=.34, p<.001\right.$; block 4 incremental $\left.R^{2}=9.9 \%\right)$. In addition to this significant direct effect for exposure to The Onion, the interaction between climate change importance and viewing The Onion was significant $(\beta=.23, p<.01$; incremental $R^{2}=5.3 \%$ ).

Displayed graphically in Figure 1, the results suggest that exposure to The Onion resulted in greater message elaboration among those who already rate the issue of climate change as personally important $(M=3.73)$ vs. those who feel the issue of climate change is important but were assigned to view TWC $(M=3.02)$. Exposure to The Onion also resulted in greater message elaboration among those for whom the issue of climate change is less important ( $M=2.85$ vs. $M=2.49$ for those who feel the issue is less important and were assigned to view TWC). Simply put, viewing the ironic one-sided satire of The Onion encouraged those who already care about climate change to further connect the comedy with what they already know from experience or related media content and also had a modest impact on those who view climate change as less important. This finding offers interesting insight with respect to $R Q 1$, suggesting that one-sided satire is particularly relevant for those who already see climate change as a personally important issue and even impactful for those who rate it as less salient. The final regression model explained $29.4 \%$ of the variance in message elaboration, telling us a great deal about the various factors that influence the differential processing of one-sided vs. two-sided humor.

\footnotetext{
${ }^{4}$ As expected, the three dependent variables are related, yet distinct components of message processing. According to the data, message discounting is correlated with message elaboration $(r=$ $.23, p<.01)$ and counterarguing $(r=.32, p<.001)$. Only the correlation between message elaboration and counterarguing is insignificant $(r=.04, p=.62)$.
} 
Table 1. Hierarchical OLS regression predicting message elaboration.

\begin{tabular}{|c|c|c|c|}
\hline & $\begin{array}{l}\text { Zero-order } \\
\text { correlations }\end{array}$ & Upon-entry & Final $\beta$ \\
\hline & \multicolumn{3}{|c|}{ Block 1: Demographics } \\
\hline Female & 16 & $.19^{*}$ & $.18^{*}$ \\
\hline Age & .06 & .09 & .06 \\
\hline Democrat & $.24^{* *}$ & $.34^{*}$ & $.34^{*}$ \\
\hline Independent & -.16 & .04 & .10 \\
\hline Conservative & -.10 & .14 & .20 \\
\hline Incremental $R^{2}$ & \multicolumn{3}{|c|}{$\begin{array}{c}9.8 \% \\
\text { Block 2: Predispositions }\end{array}$} \\
\hline Political Interest & .15 & .06 & .05 \\
\hline \multirow[t]{2}{*}{ Incremental $R^{2}$} & \multirow{2}{*}{\multicolumn{3}{|c|}{$\begin{array}{c}3.1 \% \\
\text { Block 3: Media Evaluation }\end{array}$}} \\
\hline & & & \\
\hline Media Evaluation & .15 & .12 & $.23^{* *}$ \\
\hline \multirow[t]{2}{*}{ Incremental $R^{2}$} & & $1.3 \%$ & \\
\hline & \multicolumn{3}{|c|}{ Block 4: Experimental conditions } \\
\hline The Onion & $.33^{* * *}$ & $.38^{* * *}$ & $.34^{* * *}$ \\
\hline TWC & $-.19^{*}$ & .11 & .10 \\
\hline \multirow[t]{2}{*}{ Incremental $R^{2}$} & & $9.9 \%$ & \\
\hline & \multicolumn{3}{|c|}{ Block 5: Interactions } \\
\hline Climate Importance *Onion & & & $.23^{* *}$ \\
\hline Climate Importance * TWC & & & -.02 \\
\hline Incremental $R^{2}$ & & & $5.3 \%$ \\
\hline Final $R^{2}$ & & & $29.4 \%$ \\
\hline
\end{tabular}

Discussion and conclusions
Engaging citizens with the politicized issue of climate change has been a challenge for communication researchers and policymakers alike in our crowded media environment. Recent research has started to consider whether humorous message types like satire can help engender greater participation, knowledge, and activism on the issue of climate change [Anderson and Becker, 2018; Bore and Reid, 2014; Brewer and McKnight, 2015; Brewer and McKnight, 2017; Skurka et al., 2018]. An important precursor to this satire effects research is understanding how viewers process different types of humorous messages. By exploring the differential impact of exposure to the one-sided ironic satire of The Onion vs. the more playfully sarcastic two-sided satire of TWC on message discounting, elaboration, and counterarguing, the present study places message processing at the forefront. The results ultimately suggest that more playfully sarcastic two-sided content from sources like TWC may be more likely to be quickly discounted, while ironic, highly critical, one-sided commentary offered by The Onion and other outlets encourages greater message elaboration and counterarguing. In our particular case, those who already rate the issue of climate change as important are also more likely to engage in message elaboration after exposure to The Onion's highly critical and ironic one-sided satire. At the same time, The Onion is also impactful for those who do not 


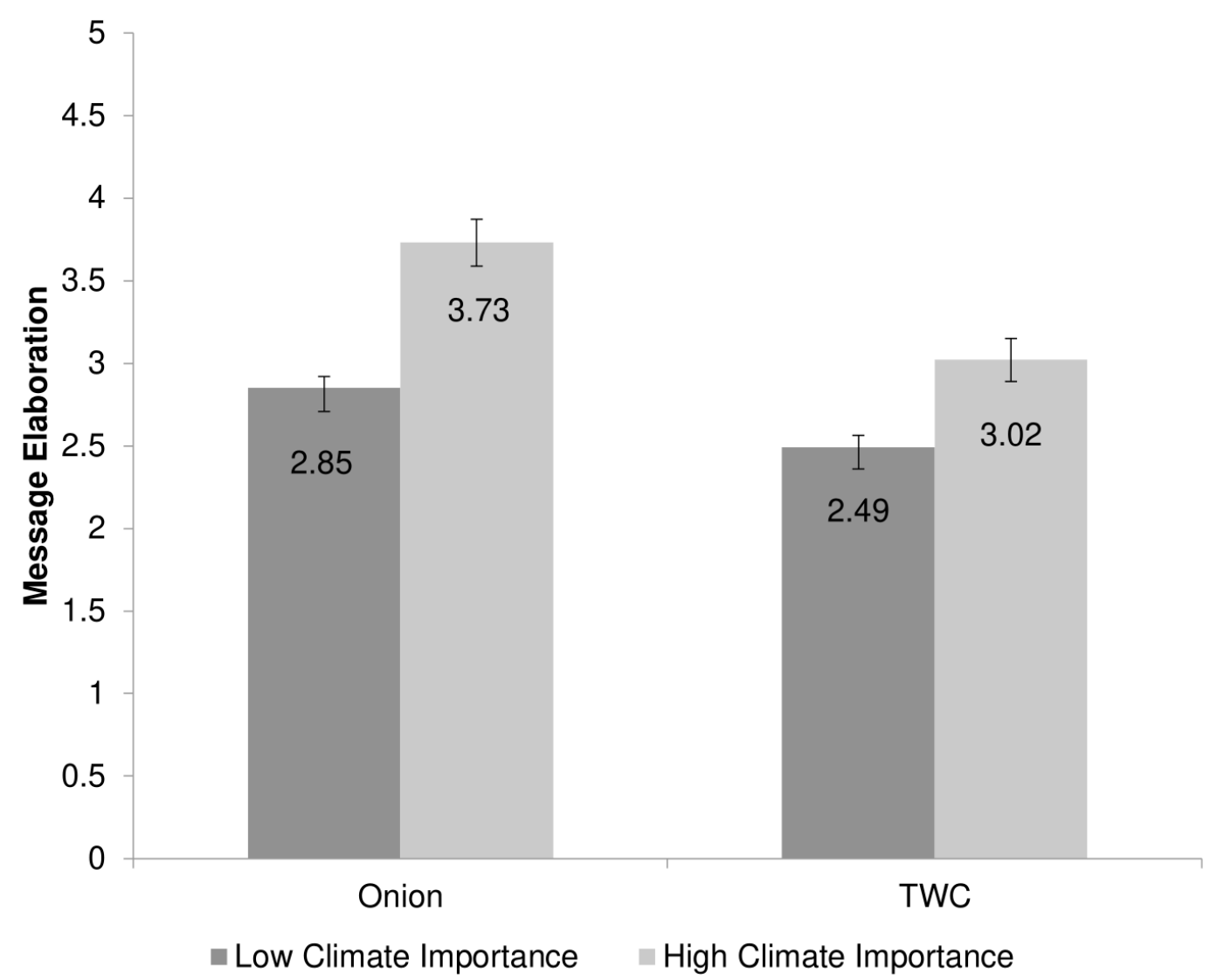

Figure 1. Message elaboration, climate change issue importance and The Onion.

rate climate change as a personally important issue. Building on what research by Anderson and Becker [2018] has recently shown, it seems that one-sided, ironic satire may be more useful as a tool for climate change engagement than more playful content that sarcastically presents both sides of the issue debate.

Research on the effectiveness of climate change communication more broadly is interested in understanding how bringing one closer to the issue may persuade them into greater concerns about, more belief in, or greater likelihood of taking action on the topic [Lyons, Hasell and Stroud, 2018]. Similar to a local weather event or an immediate health impact, humor is thought to be another means through which we can remove the psychological distance from the abstract and complex issue of climate change [Bore and Reid, 2014]. Importantly, our study adds to the growing literature that demonstrates the effectiveness of one-sided messages from sources like The Onion in reaching both those who are already highly engaged with the climate change issue and even those who are less interested from the outset. At the same time, our study suggests that two-sided humor present in mediated content popular across social media outlets is not a panacea for reaching various audiences on such a divided topic. It may be that a face-to-face setting for such humor (e.g., stand-up comedy, a theatrical presentation) is better suited to such engagement, while viral video content is simply associated with the often vitriolic nature of online discussions surrounding the climate change debate [Bore and Reid, 2014; Boykoff and Osnes, 2019]. 
Overall, our findings confirm that message sidedness, complexity, and the tone of the satire being presented are important factors worthy of careful study. One reason why the one-sided, highly critical ironic satire presented by The Onion results in greater message elaboration and counterarguing than the more playfully sarcastic two-sided satire offered by TWC may simply be that The Onion's presentation aligns with existing highly critical, one-sided satirical humor focusing on the issue of climate change that has appeared on cable television (on TDS, TCR, and $L W T$ ). The Onion gives viewers yet another example of the familiar and targets a common enemy - climate skeptics. At the same time, it may be the ironic nature of the content driving engagement, since viewers need to deeply engage with the comic text to understand that the fake climate scientist in the video doesn't really believe that global warming is a hoax. By twisting the common scientific consensus on climate change and presenting the ironic inverse of most scientists' testimony on the issue, The Onion gets viewers to pay attention in an attempt to make sense of the comic incongruity. In doing so, they think more intensively about the message (e.g., message elaboration) and at the same time, endeavor to pick apart the scientists' ironic claims (e.g., counterarguing). In contrast, the two-sided more playfully sarcastic satire presented by TWC is quickly discounted.

Before concluding, it is important to point out some of the limitations of our study. First, we rely on a small student sample ( $N=141$; with just under $n=50$ assigned to each experimental stimulus group). While our results our robust and these younger individuals are at the heart of the climate change debate and the core of the political comedy audience we recognize that relying on a convenience sample of this kind limits the generalizability of our results; future research should work to feature, larger, more representative samples. Second, our measure of message elaboration is based on self-reported behavior rather than a thought-listing type exercise that forces subjects to engage in real-time elaborative processing. Third, while we rely on a well-established, highly reliable measure of counterarguing, we recognize that some of the individual rating scales may map better onto evaluating one-sided vs. two-sided content. Nevertheless, multiple studies have used these constructs when examining cognitive responses to two-sided content [for an example, see Nisbet, Cooper and Garrett, 2015]. Lastly, we fully recognize that subjects were exposed to one short burst of video content. While we feel that incorporating additional stimuli content would have introduced unnecessary noise into our experimental design, we recognize that our findings are limited to this particular case study.

Importantly, the stimuli content is drawn from established media outlets and represents real video content subjects could easily encounter on YouTube or in their social media feeds. Privileging real world content over fake, newly produced content allows us to achieve greater ecological validity. At the same time, it is clear that the humorous stimuli we chose feature three varied elements, apart from being from different media sources: (1) the sidedness of the message (e.g. the one-sided content from The Onion vs. the two-sided presentation from TWC), (2) the tone of the humor (e.g., the critical juvenalian satire of The Onion vs. the more playful, horatian satire of $T W C$ ), and (3) the humor's complexity (e.g., the highly ironic Onion vs. the more sarcastic TWC). While we therefore cannot explicitly say whether it is the one-sidedness of the message or the tone or the complexity of the humor that leads to greater message elaboration and counterarguing after exposure to The Onion, we can suggest that at least in this experimental case, all three factors may be important and worthy of future study, especially as we seek out new ways 
to cut through the communication clutter and further engage citizens on the climate change issue. On the whole, messages that present a clear point-of-view and do so in a critical and ironic fashion have greater potential to engage viewers with the climate change debate than playful messages that sarcastically present two sides of the story.

In sum, our research suggests that highly ironic, one-sided satirical messages may serve as a useful tool for climate change engagement. Humorous messaging from The Onion and other sources may be particularly useful for individuals who already care about the issue of climate change, giving them another bit of shareable social media content to post on their news feeds and circulate among friends who might be less interested in climate change but easier to persuade given shared political outlooks. Given the highly contentious and politicized nature of the climate change debate, humorous messages may indeed serve as a useful tool to cut through the communication clutter, reducing the issue's psychological distance among like-minded communities [Bore and Reid, 2014]. Our research suggests, however, that attempts to engage individuals on the topic using two-sided messages may be less persuasive. As such, humor is not necessarily always the answer to reducing politically polarized divides on the issue of climate change. It may be more that the type of humor matters more than relying on humor in and of itself to foster engagement. Moving forward, future research should consider the intervening role of key predispositions like open-mindedness on the differential processing of onesided vs. two-sided humor on the topic of climate change [Nisbet, Hart et al., 2013].

In conclusion, our study examines the differential processing of one-sided vs. two-sided humorous messages in an attempt to complement existing research on comedy's effect on engagement with the climate change debate. We look forward to future research that continues to connect political comedy with the issue of climate change and accounts for variations in message-sidedness, tone, and humor complexity. As our research shows, we see great promise in comedy's ability to enhance the debate over climate change, promoting a more deliberative and democratic public discourse in our increasingly complex digital communications environment.

Allen, M. (1991). 'Meta-analysis comparing the persuasiveness of one-sided and two-sided messages'. Western Journal of Speech Communication 55 (4), pp. 390-404. https://doi.org/10.1080/10570319109374395.

Anderson, A. A. and Becker, A. B. (2018). 'Not just funny after all: sarcasm as a catalyst for public engagement with climate change'. Science Communication 40 (4), pp. 524-540. https://doi.org/10.1177/1075547018786560.

Becker, A. B. (2018a). 'Interviews and viewing motivations: exploring connections between political satire, perceived learning and elaborative processing'. In: Political humor in a changing media landscape: a new generation of research. Ed. by J. C. Baumgartner and A. B. Becker. Lanham, MD, U.S.A.: Lexington Books, pp. 79-94.

- (2018b). 'Live from New York, it's Trump on Twitter! The effect of engaging with Saturday Night Live on perceptions of authenticity and the saliency of trait ratings'. International Journal of Communication 12, pp. 1736-1757.

URL: http://ijoc.org/index.php/ijoc/article/view/8626/2326. 
Becker, A. B. (2012). 'Comedy types and political campaigns: the differential influence of other-directed hostile humor and self-ridicule on candidate evaluations'. Mass Communication and Society 15 (6), pp. 791-812.

https://doi.org/10.1080/15205436.2011.628431.

- (2014). 'Humiliate my enemies or mock my friends? Applying disposition theory of humor to the study of political parody appreciation and attitudes toward candidates'. Human Communication Research 40 (2), pp. 137-160. https://doi.org/10.1111/hcre.12022.

- (2017). 'Trump Trumps Baldwin? How Trump's tweets transform SNL into Trump's strategic advantage'. Journal of Political Marketing, pp. 1-19. https://doi.org/10.1080/15377857.2017.1411860.

Becker, A. B. and Bode, L. (2018). 'Satire as a source for learning? The differential impact of news versus satire exposure on net neutrality knowledge gain'. Information, Communication E Society 21 (4), pp. 612-625. https://doi.org/10.1080/1369118x.2017.1301517.

Becker, A. B. and Waisanen, D. J. (2013). 'From funny features to entertaining effects: connecting approaches to communication research on political comedy'. Review of Communication 13 (3), pp. 161-183. https://doi.org/10.1080/15358593.2013.826816.

- (2017). 'Laughing or learning with the Chief Executive? The impact of exposure to presidents' jokes on message elaboration'. Humor 30 (1). https://doi.org/10.1515/humor-2016-0056.

Bode, L. and Becker, A. B. (2018). 'Go fix it: comedy as an agent of political activation'. Social Science Quarterly 99 (5), pp. 1572-1584. https://doi.org/10.1111/ssqu.12521.

Bore, I.-L. K. and Reid, G. (2014). 'Laughing in the Face of Climate Change? Satire as a Device for Engaging Audiences in Public Debate'. Science Communication 36 (4), pp. 454-478. https://doi.org/10.1177/1075547014534076.

Boukes, M., Boomgaarden, H. G., Moorman, M. and Vreese, C. H. de (2015). 'At odds: laughing and thinking? The appreciation, processing and persuasiveness of political satire'. Journal of Communication 65 (5), pp. 721-744. https://doi.org/10.1111/jcom.12173.

Boykoff, M. T. and Boykoff, J. M. (2004). 'Balance as bias: global warming and the US prestige press'. Global Environmental Change 14 (2), pp. 125-136. https://doi.org/10.1016/j.gloenvcha.2003.10.001.

Boykoff, M. and Osnes, B. (2019). 'A laughing matter? Confronting climate change through humor'. Political Geography 68, pp. 154-163. https://doi.org/10.1016/j.polgeo.2018.09.006.

Brewer, P. R. (2013). "'Science: what's it up to?" The Daily Show and the social construction of science'. International Journal of Communication 7, pp. 452-470. URL: http://ijoc.org/index.php/ijoc/article/viewFile/1941/862.

Brewer, P. R. and McKnight, J. (2015). 'Climate as Comedy: The Effects of Satirical Television News on Climate Change Perceptions'. Science Communication 37 (5), pp. 635-657. https://doi.org/10.1177/1075547015597911.

- (2017). "“A Statistically Representative Climate Change Debate": Satirical Television News, Scientific Consensus, and Public Perceptions of Global Warming'. Atlantic Journal of Communication 25 (3), pp. 166-180. https://doi.org/10.1080/15456870.2017.1324453.

Burgers, C., van Mulken, M. and Schellens, P. J. (2011). 'Finding irony: an introduction of the Verbal Irony Procedure (VIP)'. Metaphor and Symbol 26 (3), pp. 186-205. https://doi.org/10.1080/10926488.2011.583194. 
Carrington, D. (17th May 2019). 'Why the Guardian is changing the language it uses about the environment'. The Guardian.

URL: https://www . theguardian.com/environment/2019/may/17/why-the-gua rdian-is-changing-the-language-it-uses-about-the-environment.

Compton, J. (2013). 'Inoculation theory'. In: The Sage handbook of persuasion: developments in theory and practice. Ed. by J. P. Dillard and L. Shen. Vol. 2. Thousand Oaks, CA, U.S.A.: Sage, pp. 220-237.

Compton, J. A. and Pfau, M. (2005). 'Inoculation theory of resistance to influence at maturity: recent progress in theory development and application and suggestions for future research'. Annals of the International Communication Association 29 (1), pp. 97-146. https://doi.org/10.1080/23808985.2005.11679045.

Eveland Jr., W. P. (2005). 'Information-processing strategies in mass communication research'. In: The evolution of key mass communication concepts: honoring Jack McLeod. Ed. by S. Dunwoody and L. Becker. New York, U.S.A.: Hampton Press, pp. 217-248.

Feldman, L. (2013). 'Cloudy with a chance of heat balls: the portrayal of global warming on The Daily Show and The Colbert Report'. International Journal of Communication 7 (22), pp. 430-451.

URL: http://ijoc .org/index.php/ijoc/article/view/1940/861.

- (2017). 'Assumptions about science in satirical news and late-night comedy'. In: The Oxford handbook of the science of science communication. Ed. by K. H. Jamieson, D. Kahan and D. A. Scheufele. New York, NY, U.S.A.: Oxford University Press, pp. 321-332.

Feldman, L., Leiserowitz, A. and Maibach, E. (2011). 'The science of satire: The Daily Show and The Colbert Report as sources of public attention to science and the environment'. In: The Stewart/Colbert effects: essays on the real impacts of fake news. Ed. by A. Amarasingam. Jefferson, NC, U.S.A.: McFarland, pp. 25-46.

Hale, J. L., Mongeau, P. A. and Thomas, R. M. (1991). 'Cognitive processing of oneand two-sided persuasive messages'. Western Journal of Speech Communication 55 (4), pp. 380-389. https://doi.org/10.1080/10570319109374394.

Hart, P. S. and Nisbet, E. C. (2012). 'Boomerang effects in science communication: how motivated reasoning and identity cutes amplify opinion polarization about climate mitigation policies'. Communication Research 39 (6), pp. 701-723. https://doi.org/10.1177/0093650211416646.

Hiles, S. S. and Hinnant, A. (2014). 'Climate change in the newsroom: journalists' evolving standards of objectivity when covering global warming'. Science Communication 36 (4), pp. 428-453. https://doi.org/10.1177/1075547014534077.

Holbert, R. L., Hmielowski, J., Jain, P., Lather, J. and Morey, A. (2011). ‘Adding nuance to the study of political humor effects: experimental research on Juvenalian satire versus Horatian satire'. American Behavioral Scientist 55 (3), pp. 187-211. https://doi .org/10.1177/0002764210392156.

LaMarre, H. L. and Walther, W. (2013). 'Ability matters: testing the differential effects of political news and late-night political comedy on cognitive responses and the role of ability in micro-level opinion formation'. International Journal of Public Opinion Research 25 (3), pp. 303-322.

https://doi.org/10.1093/ijpor/edt008. 
LaMarre, H. L., Landreville, K. D. and Beam, M. A. (2009). 'The irony of satire: political ideology and the motivation to see what you want to see in The Colbert Report'. The International Journal of Press/Politics 14 (2), pp. 212-231. https://doi.org/10.1177/1940161208330904.

LaMarre, H. L., Landreville, K. D., Young, D. and Gilkerson, N. (2014). 'Humor works in funny ways: examining satirical tone as a key determinant in political humor message processing'. Mass Communication and Society 17 (3), pp. 400-423. https://doi.org/10.1080/15205436.2014.891137.

Lyons, B. A., Hasell, A. and Stroud, N. J. (2018). 'Enduring extremes? Polar vortex, drought and climate change beliefs'. Environmental Communication 12 (7), pp. 876-894. https://doi.org/10.1080/17524032.2018.1520735.

Matthes, J. (2013). 'Elaboration or distraction? Knowledge acquisition from thematically related and unrelated humor in political speeches'. International Journal of Public Opinion Research 25 (3), pp. 291-302. https://doi.org/10.1093/ijpor/edt005.

Nabi, R. L., Moyer-Gusé, E. and Byrne, S. (2007). 'All joking aside: a serious investigation into the persuasive effect of funny social issue messages'. Communication Monographs 74 (1), pp. 29-54. https://doi.org/10.1080/03637750701196896.

NASA: Global Climate Change (2019). Scientific consensus: earth's climate is warming. URL: https://climate.nasa.gov/scientific-consensus/.

Niederdeppe, J., Gollust, S. E. and Barry, C. L. (2014). 'Inoculation in competitive framing'. Public Opinion Quarterly 78 (3), pp. 634-655. https://doi.org/10.1093/poq/nfu026.

Nisbet, E. C., Cooper, K. E. and Garrett, R. K. (2015). 'The partisan brain: how dissonant science messages lead conservatives and liberals to (dis) trust science'. The Annals of the American Academy of Political and Social Science 658 (1), pp. 36-66. https://doi.org/10.1177/0002716214555474.

Nisbet, E. C., Hart, P. S., Myers, T. and Ellithorpe, M. (2013). 'Attitude change in competitive framing environments? Open-/closed-mindedness, framing effects and climate change'. Journal of Communication 63 (4), pp. 766-785. https://doi.org/10.1111/jcom.12040.

Nisbet, M. C. and Scheufele, D. A. (2009). 'What's next for science communication? Promising directions and lingering distractions'. American Journal of Botany 96 (10), pp. 1767-1778. https://doi .org/10.3732/ajb.0900041.

O'Keefe, D. J. (1999). 'How to handle opposing arguments in persuasive messages: a meta-analytic review of the effects of one-sided and two-sided messages'. Annals of the International Communication Association 22 (1), pp. 209-249. https://doi.org/10.1080/23808985.1999.11678963.

Pfau, M. (1992). 'The potential of inoculation in promoting resistance to the effectiveness of comparative advertising messages'. Communication Quarterly 40 (1), pp. 26-44. https://doi.org/10.1080/01463379209369818.

Pfau, M. and Burgoon, M. (1988). 'Inoculation in political campaign communication'. Human Communication Research 15 (1), pp. 91-111. https://doi.org/10.1111/j.1468-2958.1988.tb00172.x.

Pfau, M., Park, D., Holbert, R. L. and Cho, J. (2001). 'The effects of party- and PAC-sponsored issue advertising and the potential of inoculation to combat its impact on the democratic process'. American Behavioral Scientist 44 (12), pp. 2379-2397. https://doi.org/10.1177/00027640121958384. 
Polk, J., Young, D. G. and Holbert, R. L. (2009). 'Humor complexity and political influence: an elaboration likelihood approach to the effects of humor type in The Daily Show with Jon Stewart'. Atlantic Journal of Communication 17 (4), pp. 202-219. https://doi.org/10.1080/15456870903210055.

Skurka, C., Niederdeppe, J., Romero-Canyas, R. and Acup, D. (2018). 'Pathways of influence in emotional appeals: benefits and tradeoffs of using fear or humor to promote climate change-related intentions and risk perceptions'. Journal of Communication 68 (1), pp. 169-193. https://doi.org/10.1093/joc/jqx008.

Young, D. G., Bagozzi, B. E., Goldring, A., Poulsen, S. and Drouin, E. (2019). 'Psychology, political ideology and humor appreciation: why is satire so liberal?' Psychology of Popular Media Culture 8 (2), pp. 134-147. https://doi.org/10.1037/ppm0000157.

Young, D. G. (2008). 'The privileged role of the late-night joke: exploring humor's role in disrupting argument scrutiny'. Media Psychology 11 (1), pp. 119-142. https://doi.org/10.1080/15213260701837073.

Authors

Amy B. Becker is an Associate Professor in the Department of Communication at Loyola University Maryland in Baltimore, MD. Her research examines public opinion toward controversial issues, the implications of new media technologies, and the political effects of exposure and attention to political entertainment including late night comedy. E-mail: abbecker@loyola.edu.

Ashley A. Anderson is an Associate Professor in the Department of Journalism and Media Communication at Colorado State University. Her research interests include public opinion and public engagement around issues of science and emerging technology, particularly in the online communication environment.

E-mail: Ashley.A.Anderson@colostate.edu.

\section{How to cite}

Becker, A. B. and Anderson, A. A. (2019). 'Using humor to engage the public on climate change: the effect of exposure to one-sided vs. two-sided satire on message discounting, elaboration and counterarguing'. JCOM 18 (04), A07. https://doi.org/10.22323/2.18040207. 